\title{
USE OF FUZZY LOGIC TO INVESTIGATE WEATHER PARAMETER IMPACT ON ELECTRICAL LOAD BASED ON SHORT TERM FORECASTING
}

\author{
A. Danladi1 ${ }^{1}{ }^{*}$, M. I. Puwu' ${ }^{2}$, Y. Michael ${ }^{3}$ and B. M. Garkida ${ }^{4}$ \\ 1,2,3,4 DePARTMENT OF PURE AND APPlied Physics, AdAMAWA STATE University, MUBi. AdMAWA STATE. NiGERIA. \\ E-mail addresses:1deshlangs3g@yahoo.com,2m.puwu68@yahoo.com,3yohni2003@yahoo.com, \\ 4 bulus.garkida@yahoo.com
}

\begin{abstract}
Load forecasting guides the power company to make some decisions on generation, transmission and distribution of electrical power. This work presents a solution methodology, using fuzzy logic approach for short term load forecasting (STLF) for Adamawa State University, Mubi. The proposed methodology utilized fuzzy reasoning decision rules that use the nonlinear relationships between inputs and outputs. The fuzzy logic model was developed in the Simulink environment of a MATLAB software. The model developed was able to forecast a day ahead load $(\mathrm{kW}$ ) with a mean absolute error (MAPE) of $6.17 \%$ and it was observed that weather parameter (temperature) has significant impact on electrical load.
\end{abstract}

\section{Keyword: Load forecasting, Fuzzy Logic, Rule base, Fuzzy Inference system and Short term load forecasting.}

\section{INTRODUCTION.}

Load forecasting is important for power system management; it helps in good planning, scheduling and operation of power system. Load forecasting is a technique used for predicting electrical load. Therefore, it has becomes an important tool for power companies $[3,5]$ as it gives foresight of consumers' hourly, daily, weekly and even seasonal demand. This in turn helps the company to plan maintenance schedule and operation, thereby guaranteeing energy satisfaction. Load forecasting can be divided into three categories: short-term, medium-term and long-term load forecasts [8]. In this work, design of logic system for short term electrical load forecasting is presented. STLF is a system or method of predicting electrical load with a leading time of one hour to some days. It is obvious that this method gives timely information about human activities and other factors such as weather sensitive parameters, following hourly, daily and weekly cycles $[2,4]$. In most literatures, it is practically observed that, the load demand is usually higher during the day time and in the evening $[13,14]$. Although, in the late evening, midnight and early morning the load demand is lower may be due to temperature variation. Putting this in mind shortterm forecasting can help in understanding power network reliability. Many methods have been proposed by different authors to forecast electrical load. This includes; linear regression, exponential smoothing, stochastic process, ARMA (autoregressive integrated moving average) models, and data mining models. In recent times fuzzy logic, neural network and Artificial intelligence are also used [1, 7, 9]. Fuzzy logic models have been developed as a solution forecasting method, because the weather parameters can be easily classified unlike the other techniques mentioned above [11, 6]. Also, it does not require a computational mapping of inputs to outputs or no need for precise inputs. Fuzzy logic is simply a means of representing human reasoning [12]. The main components of fuzzy logic are fuzzy set, membership function and fuzzy IF-THEN rule base. IF - THEN rule base is used to convert the fuzzy input into the fuzzy output [2]. In this research, the use of a time of the day, temperature and the previous day load will serve as the input parameters for the short term load forecasting to forecast a day ahead load. The aim of this work is to develop fuzzy logic methodology for short-term load forecasting with the following objectives: to formulate fuzzy logic rules that will facilitate the load forecasting, to compare the actual load and the forecasted load and to check the effect of 
weather parameter (temperature) on electric load. Fuzzy logic approach has been widely used in short term load forecasting by considering different factors as input variables such as weather parameters (temperature, humidity, wind speed, sun shine, light intensity, rainfall etc), time and historical load data to forecast electric load demand. In [3] short-term load forecasting was carried out using fuzzy logic methodology by considering time and weather parameters to forecast a day ahead load. The model forecasted a day ahead load with error margin of $+2.695659 \%$ to $-1.884780 \%$. Also [13] carried out a research work on "short-term load forecasting using fuzzy logic approach", in the work; short term load forecasting was proposed using time, temperature and similar previous day load as independent variables. Based on the data, rules were prepared using Mamdami implication. MATLAB SIMULINK Software was also used for system design and simulation. The research was carried out based on the load data obtained from Sudan network generation; forecasted load was obtained with an error of +12.14 to $-9.48 \%$. Also [5] proposed short term load forecasting using fuzzy logic based on weather sensitive data (temperature, humidity and wind speed) and historical load data for load forecasting. Load data used is from State Load Dispatch and Communication Centre, Rajasthan Vidyat Parasaran Nigam. The work focused on four different cases: Pre-holiday, holiday, post-holiday and working day. The forecasting performance was evaluated and MAPE (mean absolute percentage error) of the model for the four cases were presented as $10.55 \%, 9.05 \%, 10.05 \%$ and $11.74 \%$ respectively. Most of the works reviewed were presented based on the geographical factors affecting electrical load consumption and the available historical load data in their respective regions; hence their results may not be applicable to environments with different geographical factors. Therefore, this work is focused on weather parameter, temperature, time and previous day load of the area under study to forecast a day ahead load based on fuzzy logic approach for short term load forecasting.

\section{METHODOLOGY}

\subsection{Data collection and Implementation of Fuzzy Logic Procedures}

Hourly data for three days $\left(1^{\text {st }}, 2^{\text {nd }}\right.$ and $3^{\text {rd }}$ January, 2016) is collected from two departments, electrical load from maintenance unit and weather parameter (temperature) from geography department of Adamawa State University, Mubi, Adamawa state, Nigeria.

Figure 1 shows the information about the data collected. These data will be used for formulation of fuzzy logic rules.

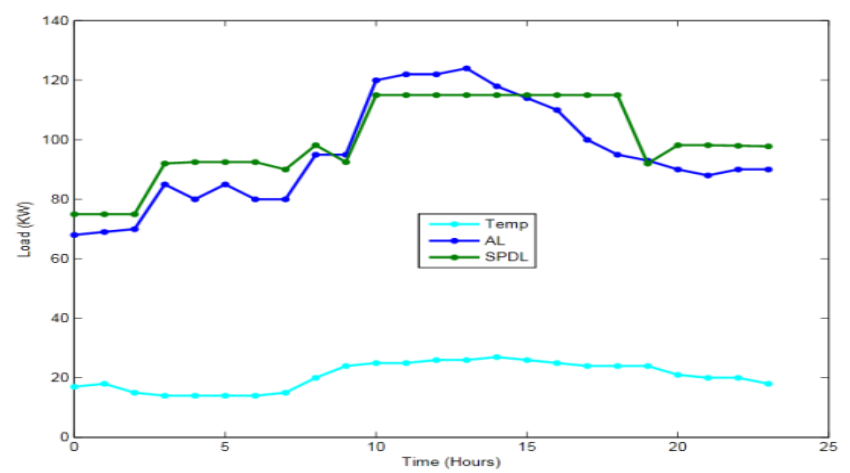

Figure 1: Previous load, Actual load Temperature vs. time

As shown in the Figure 1, it can be seen clearly that, electric load increases with increase in temperature as also shown in [10]. The minimum load obtained is at the midnight to $7.00 \mathrm{am}$ in the morning as the temperature is low. Figure 2 shows the proposed block diagram of the fuzzy model with three inputs: temperature, previous day load and time, these are fed into the fuzziffier, then the output of the fuzziffier and the fuzzy rule formulated are also fed into the fuzzy inference system (FIS) where all the information are processed. The output of the FIS is fed to the defuzzification where the crisp value of the forecasted load is produced.

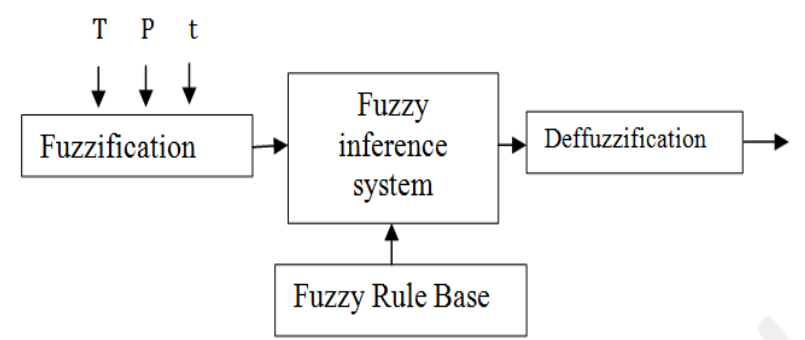

Figure 2: Block Diagram Fuzzy Logic Methodology for Short Term Load Forecasting

\subsubsection{Fuzzification}

Fuzzificationis the process whereby the crisp numerical values are fuzzified into degree of memberships related to the corresponding fuzzy sets. Several membership functions are used in fuzzy modeling, which includes trapezoidal, Gaussian, triangular etc. 
Table 1: Time classification (Hours)

\begin{tabular}{|l|l|l|l|l|l|l|l|}
\hline Classification & Midnight & Dawn & Morning & Noon & Evening & Dusk & Night \\
\hline & $0.00-$ & $4.00-$ & $7.00-$ & $12.00-$ & $15.00-$ & $18.00-$ & $21.00-$ \\
Time(Hours) & $3.00 \mathrm{am}$ & $6.00 \mathrm{am}$ & $11.00 \mathrm{am}$ & $14.00 \mathrm{pm}$ & $17.00 \mathrm{pm}$ & $20.00 \mathrm{pm}$ & $23.00 \mathrm{pm}$ \\
\hline
\end{tabular}

In this work, the triangular membership function is adopted; this membership function is flexible on all kinds of data. This is the reason for its consideration. The input data are classified as shown in Table 1.

Table 2: Classifications of Temperature $\left({ }^{\circ} \mathrm{C}\right)$ and Previous Day Load $(\mathrm{kW})$

\begin{tabular}{llll}
\hline Classifications & Low & Medium & High \\
\hline Load $(\mathrm{kW})$ & $60-95$ & $90-115$ & $110-125$ \\
Temperature $\left({ }^{\circ} \mathrm{C}\right)$ & $20-24$ & $23-27$ & $26-30$ \\
\hline
\end{tabular}

\subsubsection{Membership Function Assignment}

Membership function is a graph that defined how each point in the input space is mapped to its member value. This is usually between 0 and 1 . The membership function is mapped as depicted in Figures3 (a-d), as the time, temperature, previous day load and actual load respectively.

\subsection{Formation of fuzzy rule base}

This is the heart of the fuzzy inference system, the heuristic knowledge of the forecast is stored in terms of "IF - THEN" rules, it sends information to the fuzzy inference system, which evaluates the received information and compute the forecasted output, in this case load in $\mathrm{kW}$. The rules base is composed based on the variation of the input parameters as shown in Figure1. The fuzzy rule base is developed as follows.

- IF (time is MID-NIG), Temperature is low and the Previous Day load is low, THEN the forecasted Load is Low Load

- IF (time is MID-NIG), Temperature is low and the Previous Day Load is Medium. THEN the forecasted load is Medium Load

- IF (time is MORN), Temperature is Medium and the Previous Day Load is Low, THEN the forecasted Load is Medium Load

- IF (time is MORN), Temperature is Medium and the Previous Day Load is Medium, THEN the forecasted load is Medium Load

- IF (time is MORN), Temperature is High and the Previous Day Load is High, THEN the forecasted load is High Load

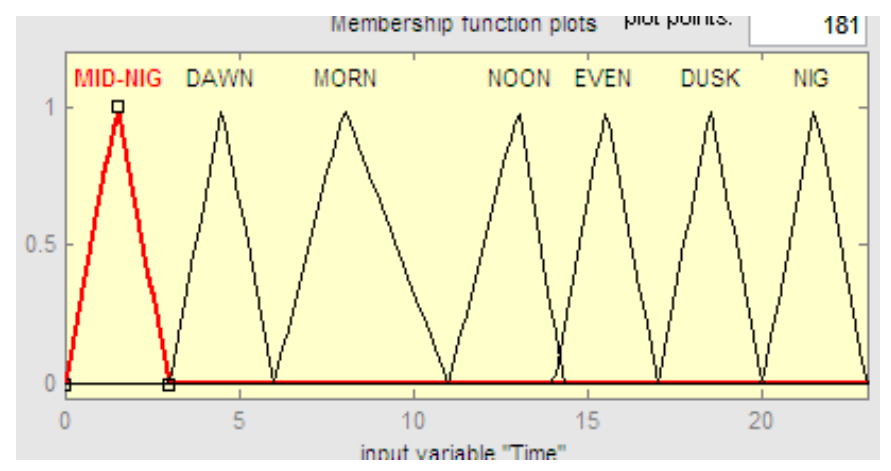

Figure3a;Membership Functions for Time

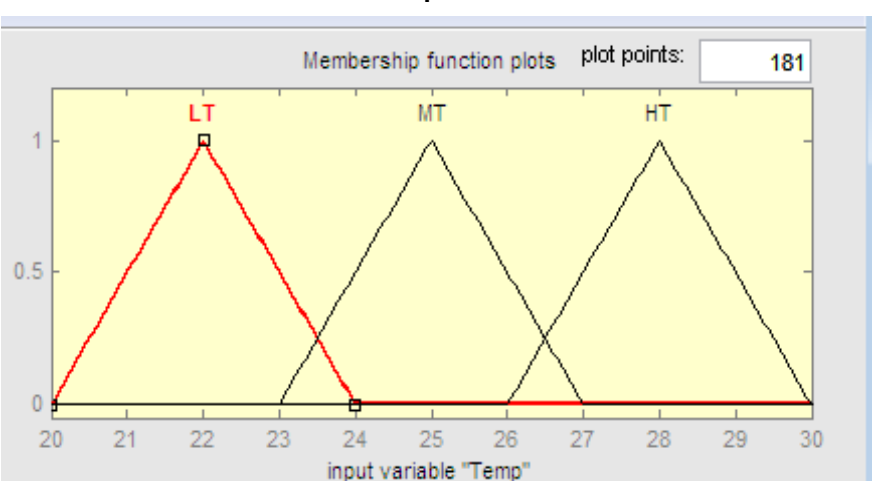

Figure 3b; Membership Function for Temperature

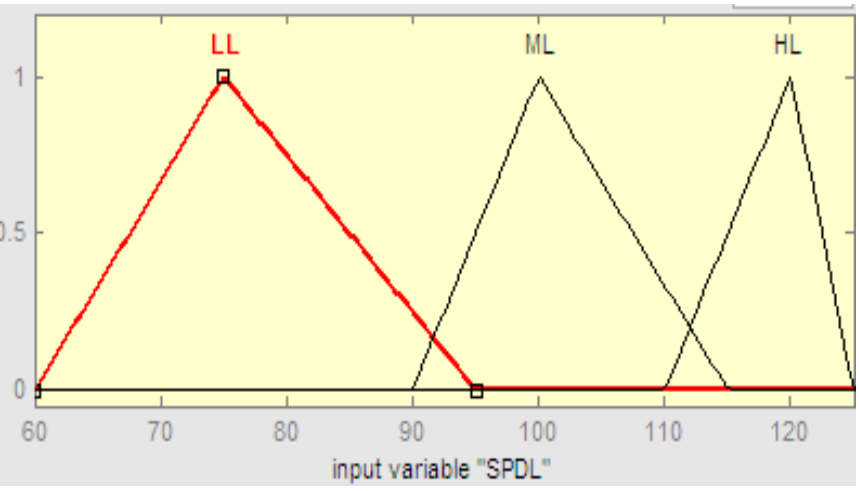

Figure 3c: Memberships Function for Previous Day Load

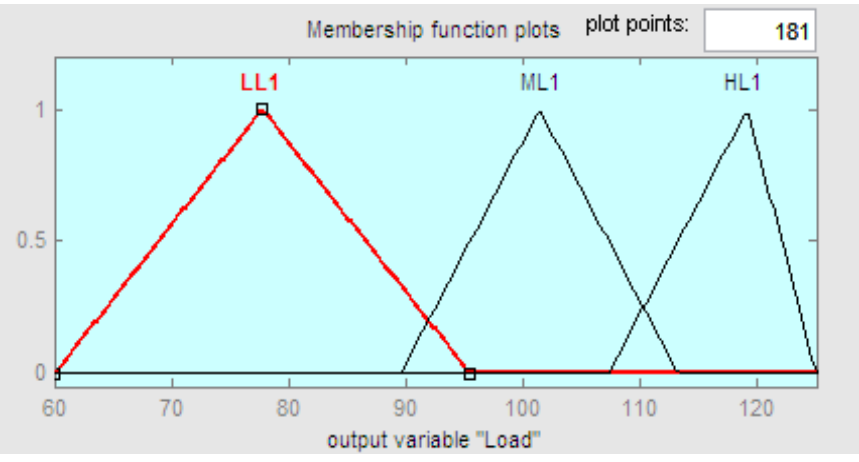

Figure 3d: Membership Functions for Actual Load 
- IF ( time is NOON), Temperature is High and the previous Day Load is High, THEN the forecasted Load is High Load

- IF( time is EVEN), Temperature is Medium and The Previous Day Load is High, THEN the forecasted load is High Load

- IF (time is DUSK), Temperature is Low and the Previous Day Load is Medium, THEN the forecasted Load is High Load

- IF ( time is DUSK), Temperature is Low and the Previous Day Load is Low, THEN the forecasted load is Medium Load

- IF( time is NIG), Temperature is low and the Previous Day Load is low, THEN the Forecasted Load is low Load

\subsection{Building of Fuzzy Logic Simulation Model}

The fuzzy model is developed as shown in Figure 2, where the three inputs are multiplexed and send to the fuzzy logic controller with rule viewer, which will process the whole information and produces a crisp output value as shown on the display of Figure4.

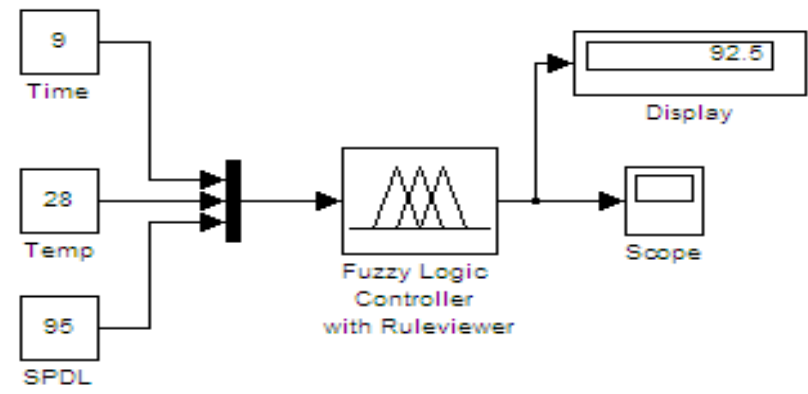

Figure 4: Fuzzy Model

For example, a sample input of Temperature $\left(28^{\circ} \mathrm{C}\right)$, the previous day load of $95 \mathrm{~kW}$ at $9.00 \mathrm{amwas}$ simulated and the forecasted load obtained is $92.5 \mathrm{~kW}$. This can also be seen on rule viewer in Figure 5
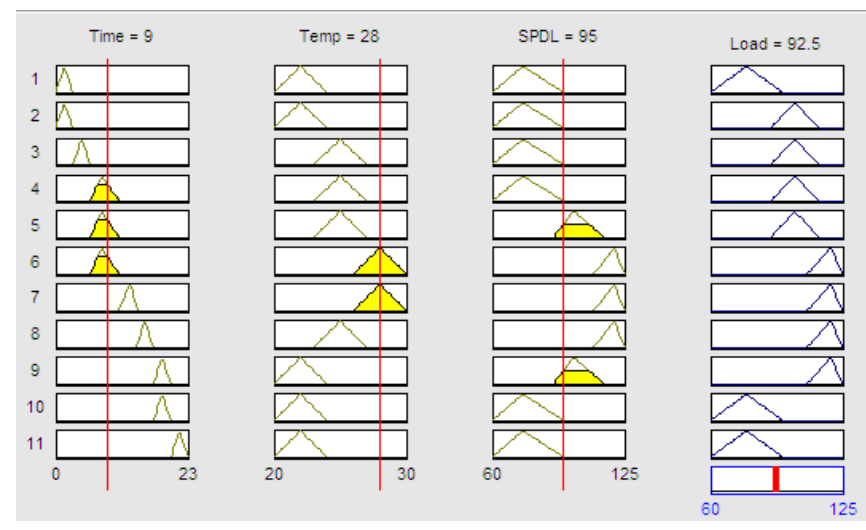

Figure 5: Fuzzy Rule Viewer
The rule viewer above shows the plots of antecedent (time, temperature and previous day load) and consequent (forecasted load).

\subsection{Error Analysis}

The absolute percentage error (APE) and the Mean

Percentage Error are calculated using Eqn. (1) and (2)

$A P E=\frac{\text { Actual Load }- \text { Forecasted Load }}{\text { Actual Load }} \times 100 \%$ (1)

$M A P E=\frac{1}{n} \sum_{i=1}^{n} \frac{\text { Actual Load }(i)-\text { Forecast Load }(i)}{\text { Actual Load }(i)}$

$\times 100 \%$

Where $\mathrm{n}=24$

\section{RESULT AND DISCUSSION}

Table 3 and Table 4 show the actual load, forecasted load and the previous day load while Table 5 shows their average values.

Table 3: Hourly Load Forecast of 2nd January 2016

\begin{tabular}{cccccc}
\hline Time(Hours) & $\begin{array}{c}\mathrm{T} \\
\left({ }^{\circ} \mathrm{C}\right)\end{array}$ & $\mathrm{P}(\mathrm{kW})$ & $\begin{array}{c}\mathrm{AL} \\
(\mathrm{kW})\end{array}$ & $\begin{array}{c}\mathrm{F} \mathrm{L} \\
(\mathrm{kW})\end{array}$ & $\begin{array}{c}\text { APE } \\
(\%)\end{array}$ \\
\hline $0.00 \mathrm{am}$ & 17 & 68.00 & 70.50 & 92.50 & 23.33 \\
$1.00 \mathrm{am}$ & 18 & 69.00 & 72.00 & 87.10 & 16.13 \\
$2.00 \mathrm{am}$ & 15 & 70.00 & 69.00 & 87.10 & 16.13 \\
$3.00 \mathrm{am}$ & 14 & 85.00 & 80.00 & 92.50 & 0.54 \\
$4.00 \mathrm{am}$ & 14 & 80.00 & 75.50 & 92.50 & 0.00 \\
$5.00 \mathrm{am}$ & 14 & 85.00 & 70.50 & 95.00 & 2.70 \\
$6.00 \mathrm{am}$ & 14 & 80.00 & 90.00 & 92.50 & 0.00 \\
$7.00 \mathrm{am}$ & 15 & 80.00 & 88.00 & 89.00 & 18.67 \\
$8.00 \mathrm{am}$ & 20 & 95.00 & 89.50 & 98.00 & 0.20 \\
$9.00 \mathrm{am}$ & 24 & 95.00 & 95.00 & 92.50 & 0.00 \\
$10.00 \mathrm{am}$ & 25 & 120.00 & 105.00 & 117.00 & 1.74 \\
$11.00 \mathrm{am}$ & 25 & 122.00 & 110.00 & 116.00 & 0.87 \\
$12.00 \mathrm{pm}$ & 26 & 122.00 & 120.00 & 117.00 & 1.74 \\
$13.00 \mathrm{pm}$ & 26 & 124.00 & 125.00 & 116.00 & 0.87 \\
$14.00 \mathrm{pm}$ & 27 & 118.00 & 120.00 & 115.00 & 0.00 \\
$15.00 \mathrm{pm}$ & 26 & 114.00 & 118.00 & 117.00 & 1.74 \\
$16.00 \mathrm{pm}$ & 25 & 110.00 & 115.00 & 92.50 & 19.57 \\
$17.00 \mathrm{pm}$ & 24 & 100.0 & 110.00 & 92.50 & 19.57 \\
$18.00 \mathrm{pm}$ & 24 & 95.00 & 100.00 & 92.50 & 19.57 \\
$19.00 \mathrm{pm}$ & 24 & 93.00 & 95.00 & 93.00 & 1.09 \\
$20.00 \mathrm{pm}$ & 21 & 90.00 & 90.00 & 92.50 & 5.80 \\
$21.00 \mathrm{pm}$ & 20 & 88.00 & 90.00 & 92.50 & 5.80 \\
$22.00 \mathrm{pm}$ & 20 & 90.00 & 88.00 & 92.00 & 6.12 \\
$23.00 \mathrm{pm}$ & 19 & 90.00 & 80.00 & 92.50 & 5.42 \\
& & & & MAPE & 6.98 \\
\hline
\end{tabular}

From Table 3, Mean Absolute Percentage Error (MAPE) is evaluated as $6.98 \%$ while the highest Absolute Percentage Error (APE) obtained is 23.33\%.To further justify the relationship between the forecasted load and the actual load; a comparison graph is plotted as shown in Figure 6 . 


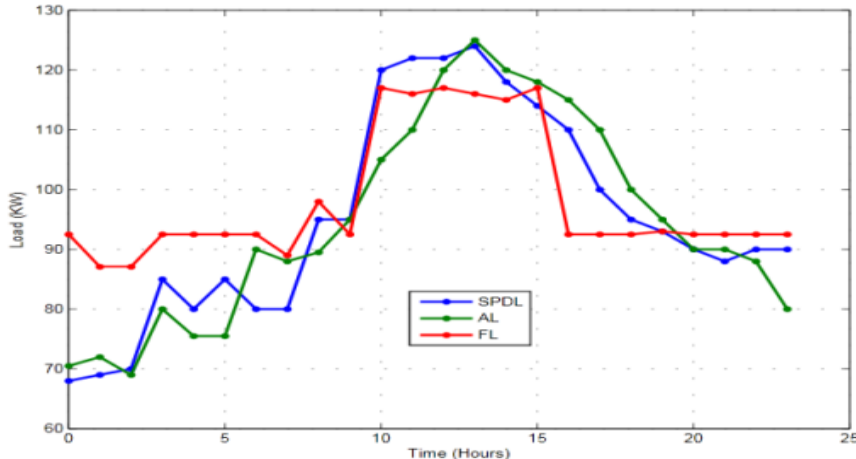

Figure6: Plots of Loads Vs Time

It is observed that, from midnight to early morning the load is low, from $10.00 \mathrm{am}$, the load increases gradually till $2.00 \mathrm{pm}$ and it starts to decrease toward the evening, it can also be seen that, the load increases as temperature increases and vice - visa. Figure 7 shows the relationship between load and time of the day as obtained in Table 4.

The graphs show similar behavior as that of $2^{\text {nd }}$ January, 2016, with low load from midnight to early morning and high load in the afternoon.

Table 4: Hourly Loads Forecasted for $3^{\text {rd }}$ January 2016

\begin{tabular}{|c|c|c|c|c|c|}
\hline Time(Hours) & $\begin{array}{c}\mathrm{T} \\
\left({ }^{\circ} \mathrm{C}\right)\end{array}$ & $\mathrm{P}(\mathrm{kW})$ & $\begin{array}{c}\mathrm{AL} \\
(\mathrm{kW})\end{array}$ & $\begin{array}{c}\text { F L } \\
(\mathrm{kW})\end{array}$ & $\begin{array}{l}\text { APE } \\
(\%)\end{array}$ \\
\hline $0.00 \mathrm{am}$ & 21.00 & 70.50 & 69.25 & 90.00 & 29.96 \\
\hline $1.00 \mathrm{am}$ & 22.00 & 72.00 & 70.50 & 90.00 & 27.66 \\
\hline 2.00am & 23.00 & 69.00 & 69.50 & 90.00 & 29.50 \\
\hline $3.00 \mathrm{am}$ & 23.00 & 80.00 & 82.50 & 90.00 & 9.09 \\
\hline $4.00 \mathrm{am}$ & 23.00 & 75.50 & 77.75 & 90.00 & 15.76 \\
\hline $5.00 \mathrm{am}$ & 24.00 & 90.00 & 87.50 & 90.00 & 2.86 \\
\hline $6.00 \mathrm{am}$ & 24.00 & 88.00 & 84.00 & 90.00 & 7.14 \\
\hline 7.00am & 26.00 & 89.50 & 84.75 & 90.00 & 6.19 \\
\hline 8.00am & 26.00 & 95.00 & 95.00 & 90.00 & 5.26 \\
\hline $9.00 \mathrm{am}$ & 28.00 & 95.00 & 95.00 & 98.20 & 3.37 \\
\hline $10.00 \mathrm{am}$ & 29.00 & 105.00 & 112.50 & 112.00 & 0.44 \\
\hline $11.00 \mathrm{am}$ & 30.00 & 110.00 & 116.00 & 113.00 & 2.59 \\
\hline $12.00 \mathrm{pm}$ & 28.00 & 120.00 & 121.00 & 112.00 & 7.44 \\
\hline $13.00 \mathrm{pm}$ & 28.00 & 125.00 & 124.50 & 112.00 & 10.04 \\
\hline $14.00 \mathrm{pm}$ & 26.00 & 120.00 & 119.00 & 112.00 & 5.88 \\
\hline $15.00 \mathrm{pm}$ & 25.00 & 118.00 & 116.00 & 112.00 & 3.45 \\
\hline $16.00 \mathrm{pm}$ & 24.00 & 115.00 & 112.50 & 112.00 & 0.44 \\
\hline $17.00 \mathrm{pm}$ & 24.00 & 110.00 & 105.00 & 90.00 & 14.29 \\
\hline $18.00 \mathrm{pm}$ & 24.00 & 100.00 & 97.50 & 90.00 & 7.69 \\
\hline $19.00 \mathrm{pm}$ & 23.00 & 95.00 & 94.00 & 90.40 & 3.83 \\
\hline $20.00 \mathrm{pm}$ & 23.00 & 90.00 & 90.00 & 90.00 & 0.00 \\
\hline $21.00 \mathrm{pm}$ & 24.00 & 90.00 & 89.00 & 90.00 & 1.12 \\
\hline $22.00 \mathrm{pm}$ & 22.00 & 88.00 & 89.00 & 90.00 & 1.12 \\
\hline \multirow[t]{2}{*}{$23.00 \mathrm{pm}$} & 22.00 & 80.00 & 85.00 & 90.00 & 5.88 \\
\hline & & & & MAPE & 8.36 \\
\hline
\end{tabular}

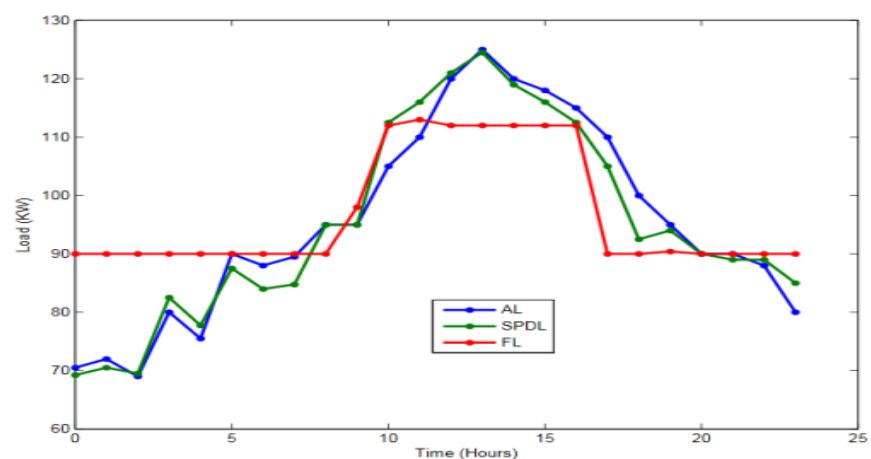

Figure 7: Relationship between the Loads

Table 5: Average Hourly Load Forecasted $2^{\text {nd }}$ and $3^{\text {rd }}$ January, 2016

\begin{tabular}{cccccc}
\multicolumn{5}{c}{ Tanuary, 2016} \\
\hline Time(Hours) & $\begin{array}{c}\mathrm{T} \\
\left({ }^{0} \mathrm{C}\right)\end{array}$ & $\begin{array}{c}\mathrm{P} \\
(\mathrm{kW})\end{array}$ & $\begin{array}{c}\mathrm{AL} \\
(\mathrm{kW})\end{array}$ & $\begin{array}{c}\mathrm{F} \mathrm{L} \\
(\mathrm{kW})\end{array}$ & $\begin{array}{c}\text { APE } \\
(\%)\end{array}$ \\
\hline $0.00 \mathrm{am}$ & 19.0 & 69.25 & 72.13 & 90.00 & 24.78 \\
$1.00 \mathrm{am}$ & 20.0 & 70.50 & 72.75 & 85.00 & 16.84 \\
$2.00 \mathrm{am}$ & 19.0 & 69.50 & 72.75 & 85.00 & 17.65 \\
$3.00 \mathrm{am}$ & 18.0 & 82.50 & 87.25 & 90.00 & 3.15 \\
$4.00 \mathrm{am}$ & 18.0 & 77.75 & 85.13 & 90.00 & 5.73 \\
$5.00 \mathrm{am}$ & 19.0 & 87.5 & 90.0 & 90.0 & 0.00 \\
$6.00 \mathrm{am}$ & 19.0 & 84.0 & 88.3 & 90.0 & 1.98 \\
$7.00 \mathrm{am}$ & 20.5 & 84.8 & 79.9 & 98.2 & 22.94 \\
$8.00 \mathrm{am}$ & 23.0 & 95.0 & 96.6 & 98.2 & 1.66 \\
$9.00 \mathrm{am}$ & 26.0 & 95.0 & 93.7 & 96.0 & 2.40 \\
$10.00 \mathrm{am}$ & 27.0 & 112.5 & 113.7 & 112.0 & 1.54 \\
$11.00 \mathrm{am}$ & 27.5 & 116.0 & 115.6 & 113.0 & 2.16 \\
$12.00 \mathrm{pm}$ & 27.0 & 121.0 & 118.0 & 112.0 & 5.08 \\
$13.00 \mathrm{pm}$ & 27.0 & 124.5 & 119.7 & 113.0 & 5.64 \\
$14.00 \mathrm{pm}$ & 26.5 & 119.0 & 117.0 & 112.0 & 4.27 \\
$15.00 \mathrm{pm}$ & 25.5 & 116.0 & 115.5 & 112.0 & 3.03 \\
$16.00 \mathrm{pm}$ & 24.5 & 112.5 & 113.8 & 112.0 & 1.54 \\
$17.00 \mathrm{pm}$ & 24.0 & 105.0 & 110.0 & 100.0 & 9.09 \\
$18.00 \mathrm{pm}$ & 24.0 & 97.5 & 100.2 & 101.0 & 4.94 \\
$19.00 \mathrm{pm}$ & 23.5 & 94.0 & 93.0 & 93.6 & 0.65 \\
$20.00 \mathrm{pm}$ & 22.0 & 90.0 & 94.1 & 90.0 & 4.36 \\
$21.00 \mathrm{pm}$ & 22.0 & 89.0 & 93.6 & 90 & 3.85 \\
$22.00 \mathrm{pm}$ & 21.0 & 89.0 & 93.5 & 90 & 3.74 \\
$23.00 \mathrm{pm}$ & 20.5 & 85.0 & 91.4 & 90.0 & 1.53 \\
& & & & $\mathrm{MAPE}$ & 6.19 \\
\hline
\end{tabular}

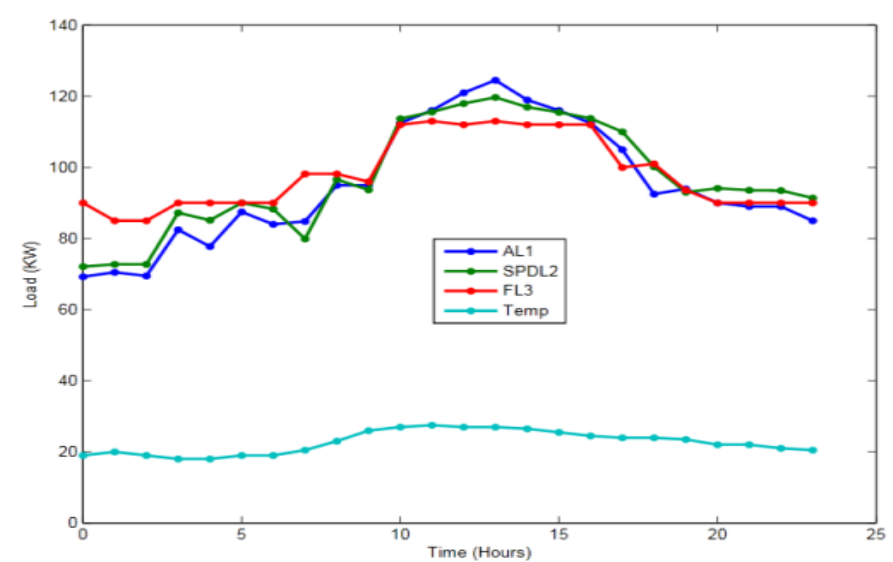

Figure 8: Average Load for $2^{\text {nd }}$ and $3^{\text {rd }}$ January, 2016 
Figure 8 presents the variation of loads with temperature and time of the day. As it can be seen, the peak load was recorded from $10.00 \mathrm{am}$ to $4.00 \mathrm{pm}$; this may be attributed to the temperature being high at that time.

\section{CONCLUSION}

In this work, fuzzy methodology for short term load forecasting is discussed. Short term load forecasting gives general information about what to generate, transmit and distribute. In this work, the following observations were made; load increases with increase in temperature and forecasted load is higher than the actual load. It is recommended that, in order to have a reliable power supply weather parameter such as temperature must be considered so that adequate information on load can be provided.

\section{REFERENCE}

[1]. Nweke, E. E, "Short term load electric power forecast in Nigeria power system using Artificial Neural Network", M. Eng Thesis, Department of Electrical Engineering, University of Nigeria. Nsukka, July 2012, pp. 1-119

[2]. Swaroop, R. and. Hussein, A. A. "Load forecasting for power system planning using fuzzy-neural network", Proceeding of the World Congress on Engineering and Computer Science, San Fransico, USA, Vol. 1, October 24-26, 2012 , pp. 1-5

[3]. Manoj,P.P and Ashish P. S.“Fuzzy logic methodology for short load forecasting", International Journal of Research in Engineering and Technology Vol. 03, Issue 04, April, 2014. pp 1-7

[4]. Zuhaimy I and Johor, D. T. "Fuzzy Logic approach for Forecasting Half-hourly Malaysia Electricity Load demand", Department of Mathematics, Universiti Teknologi Malaysia and School of Quantitative Sciences, Universiti Utara Malaysia 06010 Sintok Kedah Malaysia. July 22, 2011, pp. 117.
[5]. Priti, G. and Monika, G. "Short Term Load Forecasting using Fuzzy Logic", International Journal of Engineering Development and Research (Two Day National Conference) 17th -18th January, 2014. pp. 1-4

[6]. Hong T, "Short- term Electric load forecasting", PHD Thesis, Graduate Faculty of North Carolina State University, October, 2010, pp. 1-175.

[7]. Sanjib, M, "Short term load forecasting using Computational Intelligence Method", M. Tech. Thesis, Department of Electronics and Communication Engineering National Institute of Technology, Rounkela, 2008 pp. 1-89

[8]. Jagbir, K.and Yadwinder, S. B, “Short-term Electrical Forecasting using fuzzy logic 220kVA Transmission Line", International Journal of Research in Engineering and Technology, vol.3, Issue 9, September, 2014, PP 1-4

[9]. Muhammad, R. K. and Ajik A. "Short term load forecasting models Czech Republic using soft computing paradigms", Department of Computer Science, Oklahoma State University, Tulsa, OK 74106-0700, USA,2000, pp. 1-8.

[10]. Tai H. F., "Case Study of Short- term Electricity Load Forecasting with Temperature Dependency" M. Sc Thesis, Faculty of Electrical and Electronics Engineering, University Malaysia, 2009, PP. 1-24

[11]. Hari S. and Saravanan, R."Short term electric load prediction Using Fuzzy BP", Journal of Computing and Information Technology, Vol. 3, 2007, pp.1 - 15.

[12]. Zaria M. S, "Short term Electrical Load Forecasting Using Fuzzy Logic", M.Sc. Thesis, Sudan University of Science and Technology College of Graduate Studies Nov, 2015, pp. 1-45.

[13]. Priti Gohil and Monika Gupta "Short term load forecasting using logic" International Journal of Engineering Development and Research, Jan, 2014, pp. $127-130$.

[14] Song, K. B, Ha, S. K., Park, J. W., Kweon D. J., and Kim, K. H, "Hybrid load forecasting method with analysis of temperature sensitivities, IEEE Trans. Power Systems, Vol. 22, No. 2 2006.pp. 869 - 876. 